\title{
From x-phi to bioxphi: Lessons in Conceptual Analysis 2.0
}

\section{Jonathan Lewis}

To cite this article: Jonathan Lewis (2020) From x-phi to bioxphi: Lessons in Conceptual Analysis 2.0, AJOB Empirical Bioethics, 11:1, 34-36, DOI: 10.1080/23294515.2019.1705430

To link to this article: https://doi.org/10.1080/23294515.2019.1705430

曲 Published online: 25 Feb 2020.

Submit your article to this journal 준

Q View related articles $\widetilde{ }$

View Crossmark data 


\title{
From x-phi to bioxphi: Lessons in Conceptual Analysis 2.0
}

\author{
Jonathan Lewis
}

Institute of Ethics, Faculty of Humanities and Social Sciences, Dublin City University, Dublin, Ireland

\section{Introduction}

John McMillan (2018) argues that "good bioethics" requires us to clarify and distinguish bioethical concepts in order to generate arguments that meet the needs of patients, practitioners, and policymakers. One of the premises for this claim is that, depending on how it is employed in discursive practices, a concept can underwrite several different inferences with contrasting moral implications. Consequently, one way to clarify the contents of a concept is to see how it is used and to infer content from use. Such an approach gestures at a second premise, namely, that conceptual analysis should be empirically informed if it is to meet the needs of the medical community. The empirical task of inferring the content of a concept from actual discursive practices cannot be reconciled with the traditional picture of conceptual analysis, whereby, from the comfort of the armchair, the analyst aims to provide necessary and sufficient semantic or epistemological conditions for the application of a concept. Instead, one way in which "good bioethics" can analyze bioethical concepts is to draw upon developments in experimental philosophy ("x-phi”). This approach to conceptual analysis distinguishes itself from those methods that have been popular in related areas, particularly in nursing science (Rodgers, Jacelon, and Knafl 2018). Rather than using literature reviews to elucidate concepts, $\mathrm{x}$-phi-inspired approaches primarily employ controlled experiments. Rather than constructing or identifying cases that illustrate or identify features associated with a concept, this naturalized approach to conceptual analysis aims to make explicit the contextual, demographic, and psychological factors underpinning the way people think about specific bioethical concepts, to identify and distinguish the inferences these concepts dispose them to draw, and to clarify the moral implications of each particular concept.
Finally, rather than present descriptive analyses as the endpoint of inquiry, this approach to experimental philosophical bioethics-or "bioxphi" (Earp et al. 2019a)-employs conceptual analyses not only to inform normative arguments, but to modify our inferences and reform our bioethical concepts so as to facilitate evidence-based changes to both policy and practice.

\section{Conceptual analysis $\mathbf{2 . 0}$}

Experimental philosophers have provided evidence for the divergence between philosophers' concepts and those of nonphilosophers. They have also shown that different groups possess different concepts due to the influence of demographic variables such as culture, age, personality, and socioeconomic status (Machery 2017, 45-89). These findings have led Édouard Machery (2017) to argue that philosophers should be interested in how nonphilosophers think about various topics, a claim that is perhaps even more pertinent in the context of bioethics. For instance, McMillan $(2018,38)$ illustrates that physicians often object to James Rachels's (1975) philosophical attempt to call into question the moral difference between active and passive euthanasia on the basis that it does not adequately capture concrete normative and empirical issues in end-of-life decisions. If we, as members of the medical community, want to know the clinical significance of the concept of euthanasia, then we are unlikely to be interested in purely philosophical reflections that raise a specific point about the nature of intentional action in isolation from clinical practices. Indeed, lay concepts frequently allow us to practically navigate situations despite the absence of an overarching philosophical definition. After all, the lay distinction between active and passive euthanasia has enabled the medical community to navigate the ethico-legal terrain more

CONTACT Jonathan Lewis jonathan.lewis@dcu.ie Dublin City University, Institute of Ethics, Faculty of Humanities and Social Sciences, School of Theology, Philosophy and Music, Senior House, All Hallows Campus, Dublin, Ireland.

(C) 2020 Taylor \& Francis Group, LLC 
successfully: for example, by introducing conceptual distinctions between euthanasia, physician-assisted suicide (PAS), palliative sedation, and withdrawing life-sustaining treatment. In addition, despite Rachels's claim that the distinction between two different types of euthanasia rests on a difference between killing and letting die that has no moral importance, evidence from numerous studies shows that the folk-conceptual distinction between "doing" and "allowing" harm is of vital normative significance to ordinary people ("folk") (Cushman, Knobe, and Sinnott-Armstrong 2008).

$\mathrm{X}$-phi not only provides evidence that affirms the practical importance of lay concepts; it employs the methods of experimental psychology to examine the folk concepts that matter, making explicit the structures underpinning the way folk think about the extensions of concepts and identifying the inferences concepts dispose them to draw. Having recently been employed for bioethical ends, such experimental methods highlight the normative significance of a rebooted approach to concept analysis-Conceptual Analysis 2.0.

\section{What is the normative significance of Conceptual Analysis 2.0?}

Both McMillan (2018) and Machery (2017) argue that we do not automatically know what discursive partners think about a topic when they use a particular concept. Everyday (bioethical) concepts are often unclear and can lead to fundamental disagreements concerning our obligations. On the basis that concepts determine the inferences we are prone to draw, clarifying and distinguishing these inferences comprise one of the reasons why the analysis of the way people think about various concepts matters. For example, Faber, Savulescu, and Douglas (2016) have undertaken a naturalized approach to conceptual analysis in order to advance research on the perceived unacceptability of cognitive enhancement (CE). In light of the concepts of unfairness, hollowness, and undeservingness, the analysis reveals that the lay concept of CE disposes participants to draw inferences concerning unfairness. By contrast, in order to explain the perceived unacceptability of $\mathrm{CE}$, the other two concepts are not necessary. In this instance, Conceptual Analysis 2.0 reveals that the acceptability of $\mathrm{CE}$ is partly determined by lay attitudes regarding equality.

As McMillan (2018, 154-45) demonstrates in the case of the concept "futility," there can also be more than one concept with the same name. He observes that physicians deem medical treatment to be futile if it is very unlikely to improve the well-being of the patient. Additionally, physicians employ the concept of futility when a treatment does not succeed as treatment, regardless of their beliefs concerning the patient's well-being. McMillan eliminates the confusion by drawing a distinction between two concepts of medical futility on the basis of how they are used. If such distinctions are not made, then this can lead to incompatible claims about the contents of a certain concept, as well as disagreements concerning one's obligations.

How conceptual distinctions are drawn, and the names that we give to those concepts, play an important role in how we proceed with clinical practice and public policy. For instance, a recent bioxphi study has shown that lay attitudes to $\mathrm{CE}$ depend upon the metaphors employed, such as when CE is framed as fuel, cosmetics, steroids, or hacking (Conrad, Humphries, and Chatterjee 2019). Different framing metaphors underwrite different inferences; the "fuel" metaphor increases and the "steroids" metaphor decreases the acceptability of CE use. If these results are generalizable, then the contrasting inferences may help guide proponents in policy development by employing framing concepts that enhance the perceived acceptability of CE.

By way of another example, an experimental study into the lay concept of addiction has revealed that when a drug is framed as medicine in one condition and as an addictive drug in another, the latter leads to higher ratings for perceived identity change in addicted individuals (Earp et al. 2019b). In terms of the normative significance of the study, the analysis suggests that if the way individuals think about identity change is affected by a person's addiction due to a presumed diminishment in the latter's moral character, then this has profound consequences for how individuals actually relate to persons with addiction. Consequently, Earp suggests that framing treatment in relation to the concept of identity change may be a useful way of overcoming some of the barriers to successful addiction treatment.

What experimental studies like these show is that it is usually not enough when clarifying and distinguishing inferences to merely demonstrate that one lay concept is different from another. Insofar as "good bioethics" is about generating cogent arguments that are of normative significance to the medical community, it is also necessary to clarify the different moral implications of bioethical concepts. 
If the first goal of experimental conceptual analysis is descriptive, then, according to Machery (2017), the second goal is prescriptive; Conceptual Analysis 2.0 seeks to modify those inferences that are deficient, reform concepts, or eschew certain concepts entirely.

As is the case with our beliefs, the concepts we use can contain false information or lead to inferences that are unreliable. For example, if one erroneously concludes that the act of euthanasia requires a physician to provide a patient with the means to take their own life without the physician taking a deliberate role in ending life by some medical means, then the concept of euthanasia must be modified since the two acts are considered to be conceptually distinct. In this case, conceptual modification has already occurred, with the distinction between PAS and "voluntary active euthanasia" encapsulating important normative differences for end-of-life decisions.

Finally, a concept may need to be reformed or eschewed if it is perceived to have undesirable moral implications. For instance, the terminology employed in the context of PAS has been the subject of controversy, with proponents of legalization arguing that the concept "suicide" is likely to bias health care practitioners against assisted dying. However, a naturalized conceptual analysis has shown that that there is no evidence that the concept prejudices clinicians against PAS; in fact, the results trended in the opposite direction (Braverman et al. 2017). If such results are generalizable, then they provide empirically grounded reasons that can be used to inform normative arguments in the context of the debates regarding assisted dying.

\section{Conclusion}

The examples provided here demonstrate the ways in which experimental conceptual analysis is already a vital feature of the broader bioxphi movement. By bringing together the experimental and normative dimensions of bioethics, bioxphi not only allows us to make sense of the ways people think about the bioethical concepts they use, but also seeks to understand their normative significance for research, policy, and practice.

\section{Acknowledgments}

I gratefully acknowledge the respective contributions of Holly Taylor, Theodore Schall, and the anonymous reviewer at $A J O B$ Empirical Bioethics.

\section{Author contributions}

The author was the sole contributor to the conception, design, data collection, drafting, and revision of this work.

\section{Funding}

None.

\section{Conflicts of interest}

None.

\section{Ethical approval}

Not applicable.

\section{ORCID}

Jonathan Lewis (iD http://orcid.org/0000-0001-8342-1051

\section{References}

Braverman, D. W., B. S. Marcus, P. G. Wakim, M. R. Mercurio, G. S. Kopf, et. al. 2017. Health care professionals' attitudes about physician-assisted death: An analysis of their justifications and the roles of terminology and patient competency. Journal of Pain and Symptom Management 54 (4): 538-45. doi: 10.1016/j.jpainsymman.2017.07.024.

Conrad, E.C., S. Humphries, and A. Chatterjee. 2019. Attitudes toward cognitive enhancement: The role of metaphor and context. AJOB Neuroscience 10 (1):35-47. doi: 10.1080/21507740.2019.1595771.

Cushman, F., J. Knobe, and W. Sinnott-Armstrong. 2008. Moral appraisals affect doing/allowing judgments. Cognition 108 (1):281-9. doi: 10.1016/j.cognition.2008.02.005.

Earp, B.D., J. Demaree-Cotton, M. Dunn, et al. 2019a. Experimental philosophical bioethics. AJOB Empirical Bioethics. https://kar.kent.ac.uk/id/eprint/78633.

Earp, B.D., J.A. Skorburg, J.A.C. Everett, and J. Savulescu. 2019b. Addiction, identity, morality. AJOB Empirical Bioethics 10 (2):136-53. doi: 10.1080/23294515.2019.1590480.

Faber, N.S., J. Savulescu, and T. Douglas. 2016. Why is cognitive enhancement deemed unacceptable? The role of fairness, deservingness, and hollow achievements. Frontiers in Psychology 7 (232):1-12. doi: 10.3389/fpsyg.2016.00232.

Machery, E. 2017. Philosophy within its proper bounds. Oxford: Oxford University Press.

McMillan, J. 2018. The methods of bioethics: An essay in meta-bioethics. Oxford: Oxford University Press.

Rachels, J. 1975. Active and passive euthanasia. New England Journal of Medicine 292 (2):78-80. doi: 10.1056/ NEJM197501092920206.

Rodgers, B.L., C.S. Jacelon, and K.A. Knafl. 2018. Concept analysis and the advance of nursing knowledge: state of the science. Journal of Nursing Scholarship 50 (4):451-9. doi: 10.1111/jnu.12386. 